\title{
Association between pre-hospital vitamin D status and hospital-acquired new-onset delirium
}

\author{
Sadeq A. Quraishi ${ }^{1,2}$, Augusto A. Litonjua ${ }^{3,4}$, Kevin M. Elias ${ }^{5}$, Fiona K. Gibbons ${ }^{3,6}$, \\ Edward Giovannucci ${ }^{7,8}$, Carlos A. Camargo $\mathrm{Jr}^{3,8,9}$ and Kenneth B. Christopher ${ }^{3,10 *}$ \\ ${ }^{1}$ Department of Anaesthesia, Harvard Medical School, Boston, MA, USA \\ ${ }^{2}$ Department of Anesthesia, Critical Care and Pain Medicine, Massachusetts General Hospital, Boston, MA, USA \\ ${ }^{3}$ Department of Medicine, Harvard Medical School, Boston, MA, USA \\ ${ }^{4}$ Channing Division of Network Medicine and Pulmonary and Critical Care Division, Department of Medicine, \\ Brigham and Women's Hospital, Boston, MA, USA \\ ${ }^{5}$ Department of Obstetrics and Gynecology, Brigham and Women's Hospital, Boston, MA, USA \\ ${ }^{6}$ Division of Pulmonary and Critical Care Medicine, Department of Medicine, Massachusetts General Hospital, \\ Boston, MA, USA \\ ${ }^{7}$ Department of Nutrition, Harvard School of Public Health, Boston, MA, USA \\ ${ }^{8}$ Department of Epidemiology, Harvard School of Public Health, Boston, MA, USA \\ ${ }^{9}$ Department of Emergency Medicine, Massachusetts General Hospital, Boston, MA, USA \\ ${ }^{10}$ The Nathan E. Hellman Memorial Laboratory, Renal Division, Department of Medicine, Brigham and Women's Hospital, \\ 75 Francis Street, MRB 418, Boston, MA 02115, USA
}

(Submitted 5 August 2014 - Final revision received 7 February 2015 - Accepted 17 March 2015 - First published online 21 April 2015)

\section{Abstract}

The goal of the present study was to determine whether pre-hospital 25-hydroxyvitamin D (25(OH)D) levels are associated with the risk of hospital-acquired new-onset delirium (HANOD). We performed a retrospective cohort study of 4508 adult inpatients at two teaching hospitals in Boston from 1993 to 2006. All patients had 25(OH)D levels measured before hospital admission. The main outcome measure was HANOD, defined as the onset of delirium during an acute care hospitalisation. Patients with a history of delirium or dementia, or those with a diagnosis of delirium or dementia upon acute care hospitalisation were excluded from the analysis. To test the association of pre-hospital 25(OH)D levels with HANOD, we constructed a multivariable logistic regression model to adjust for clinically relevant covariates. Among our patient cohort, the mean 25(OH)D level was $22(\mathrm{sD} 13) \mathrm{ng} / \mathrm{ml}$ and approximately $4 \%$ of patients met the criteria for HANOD. Following adjustment for age, sex, race (non-white $v$. white), patient type (medical $v$. surgical) and Deyo-Charlson Index, patients with 25(OH)D levels $<10,10-19.9$ and $20-29.9 \mathrm{ng} / \mathrm{ml}$ had higher odds of HANOD than patients with 25(OH)D levels $\geq 30 \mathrm{ng} / \mathrm{ml}$ : OR $2 \cdot 15$ (95\% CI $1.32,3.50)$, OR $1.54(95 \% \mathrm{CI} 0.98,2.43)$ and OR $1.23(95 \% \mathrm{CI}, 0.76,1.99)$, respectively. These data support the rationale for randomised, controlled trials to test the role of vitamin D supplementation in the prevention of HANOD.

Key words: Vitamin D: 25-Hydroxyvitamin D: Delirium: Nosocomial infections: Hospital-acquired new-onset delirium

Delirium is a complex neuropsychiatric syndrome defined by five key elements: (1) a disturbance of attention; (2) a change in cognition; (3) a rapid onset; (4) a fluctuating course; (5) history, physical examination or laboratory findings which suggest that the disturbance is caused by a direct physiological consequence of a general medical condition, an intoxicating substance, medication use or more than one cause ${ }^{(1)}$. It is commonly encountered in health care settings and has an occurrence rate between 11 and 56\% in hospitalised patients ${ }^{(2,3)}$. While many patients may have a pre-existing history of delirium or another neurocognitive disorder (e.g. dementia) that significantly increases the risk of delirium in an institutionalised setting ${ }^{(4-6)}$, the incidence of hospital-acquired new-onset delirium (HANOD) in otherwise 'low-risk' individuals is estimated to be between 3 and $29 \%^{(2)}$. On average, patients who develop HANOD remain hospitalised $4-13 \mathrm{~d}$ longer than their non-delirious counterparts $^{(7)}$. There is also a 2-fold increased risk of mortality at 12 months when patients who develop HANOD are compared with those who remain free of delirium ${ }^{(2)}$

Abbreviations: 25(OH)D, 25-hydroxyvitamin D; HANOD, hospital-acquired new-onset delirium; RPDR, Research Patient Data Registry.

*Corresponding author: K. B. Christopher, fax +1617 726 3032, email kbchristopher@partners.org 
In the USA, annual health care expenditures attributable to HANOD are estimated to be $\$ 38-152$ billion $^{(8)}$.

The underlying cause of delirium is often multifactorial ${ }^{(9)}$. Age, sex, medical comorbidities, recent surgery and history of cognitive impairment are all known risk factors for delirium in hospitalised patients ${ }^{(7,9)}$. Recently, with the discovery of vitamin $\mathrm{D}$ receptors in the human cortex and hippocampus (areas critical for intact cognition) ${ }^{(10)}$, the role of vitamin D status in neuropsychiatric disorders has become an area of active investigation ${ }^{(11,12)}$. Indeed, levels of the best serum marker of vitamin D status, 25-hydroxyvitamin D $(25(\mathrm{OH}) \mathrm{D})$, have been shown to be associated with the risk of dementia ${ }^{(13)}$, Alzheimer's disease ${ }^{(14)}$ and depression ${ }^{(15)}$. Given the high prevalence of suboptimal 25(OH)D levels in the general population of the USA ${ }^{(16-20)}$, we performed a two-centre observational study of hospitalised adult patients. The objective of the present study was to investigate whether vitamin D status before hospital admission is associated with an increased risk of developing HANOD.

\section{Materials and methods}

\section{Source population}

We abstracted administrative and laboratory data from individuals who were hospitalised at one of two teaching hospitals in Boston, Massachusetts: Brigham and Women's Hospital, with 777 beds, and Massachusetts General Hospital, with 902 beds. These two hospitals provide primary and tertiary care to an ethnically and socioeconomically diverse population within and around Eastern Massachusetts.

\section{Data sources}

We obtained data on all patients admitted to Brigham and Women's Hospital or Massachusetts General Hospital between August 1993 and November 2006 through the Research Patient Data Registry (RPDR). RPDR is a computerised registry, which serves as a central data warehouse for all inpatient and outpatient records at Partners HealthCare facilities (including Brigham and Women's Hospital and Massachusetts General Hospital). The registry has been used for multiple clinical research studies ${ }^{(21-25)}$. The Institutional Review Board approval for the study was granted by the Partners Human Research Committee.

\section{Study population}

We identified 5341 individual patient admissions (age $\geq 18$ years) over the study period that were assigned a Diagnostic Related Group and that had documented serum 25(OH)D measurements between 7 and $365 \mathrm{~d}$ before hospitalisation. The Diagnostic Related Group is a nationwide classification system used by hospitals in the USA to categorise the expected resource utilisation for a specific medical case (e.g. heart failure exacerbation, appendectomy). We then excluded five foreign patients without Social Security Numbers since vital status in the present study was determined by the Social Security Administration Death Master File, and 828 patients who had existing history of delirium or dementia, or a diagnosis of delirium or dementia upon hospitalisation. The final study cohort was therefore composed of 4508 patients.

\section{Exposure and outcome of interest}

The exposure of interest was pre-admission serum 25(OH)D level obtained 7-365d before the date of hospitalisation. $25(\mathrm{OH}) \mathrm{D}$ levels were categorised a priori as $<10,10-19 \cdot 9$, $20-29 \cdot 9$ and $\geq 30 \mathrm{ng} / \mathrm{ml}$. All cut points were adapted from the Endocrine Society clinical practice guidelines ${ }^{(26)}$. Serum $25(\mathrm{OH}) \mathrm{D}$ in all cohort subjects was determined by RIA utilising the DiaSorin Corporation 25-Hydroxyvitamin D 125I RIA $\mathrm{kit}^{(27)}$. Inter- and intra-assay $\mathrm{CV}$ were both $<10 \%$. The primary outcome of interest was the presence of HANOD. HANOD was defined as the new presence of International Classification of Disease, 9th Revision, Clinical Modification (ICD-9-CM) codes related to delirium: 290.11, 290.3, 290.41,

Table 1. Baseline demographic characteristics of the study population (Number of subjects and percentages; mean values and standard deviations)

\begin{tabular}{|c|c|c|c|c|c|c|}
\hline & \multicolumn{2}{|c|}{$\begin{array}{l}\text { Non- } \\
\text { HANOD }\end{array}$} & \multicolumn{2}{|c|}{ HANOD } & \multicolumn{2}{|c|}{ Total } \\
\hline & $n$ & $\%$ & $n$ & $\%$ & $n$ & $\%$ \\
\hline Total number of cases & \multicolumn{2}{|c|}{4309} & \multicolumn{2}{|c|}{199} & \multicolumn{2}{|c|}{4508} \\
\hline Age (years) & & & & & & \\
\hline Mean & \multicolumn{2}{|c|}{59} & \multicolumn{2}{|c|}{67} & \multicolumn{2}{|c|}{59} \\
\hline SD & \multicolumn{2}{|c|}{18} & \multicolumn{2}{|c|}{18} & \multicolumn{2}{|c|}{18} \\
\hline \multicolumn{7}{|l|}{ Sex } \\
\hline Female & 2836 & 66 & 125 & 63 & 2961 & 66 \\
\hline Male & 1473 & 34 & 74 & 37 & 1547 & 34 \\
\hline \multicolumn{7}{|l|}{ Race } \\
\hline White & 3606 & 84 & 168 & 84 & 3774 & 84 \\
\hline Non-white & 703 & 16 & 31 & 16 & 734 & 16 \\
\hline \multicolumn{7}{|l|}{ Patient type } \\
\hline Medical & 2517 & 58 & 138 & 69 & 2655 & 59 \\
\hline Surgical & 1792 & 42 & 61 & 31 & 1853 & 41 \\
\hline \multicolumn{7}{|l|}{ Deyo-Charlson Index } \\
\hline $0-3$ & 1969 & 46 & 48 & 24 & 2017 & 45 \\
\hline $4-6$ & 1103 & 26 & 62 & 31 & 1165 & 26 \\
\hline$\geq 7$ & 1237 & 29 & 89 & 45 & 1326 & 29 \\
\hline Recent surgery & 150 & 4 & 9 & 5 & 159 & 4 \\
\hline $\begin{array}{l}\text { Psychiatric primary } \\
\text { diagnosis }\end{array}$ & 62 & 1.4 & 3 & 1.5 & 65 & 1.4 \\
\hline Antipsychotic medications & 174 & 4 & 72 & 36 & 246 & 5 \\
\hline $\begin{array}{l}\text { Major depressive } \\
\text { disorder history }\end{array}$ & 134 & 3 & 14 & 7 & 148 & 3 \\
\hline \multicolumn{7}{|l|}{$25(\mathrm{OH}) \mathrm{D}(\mathrm{ng} / \mathrm{ml})$} \\
\hline Mean & \multicolumn{2}{|c|}{22} & \multicolumn{2}{|c|}{19} & \multicolumn{2}{|c|}{22} \\
\hline SD & \multicolumn{2}{|c|}{13} & \multicolumn{2}{|c|}{11} & \multicolumn{2}{|c|}{13} \\
\hline \multicolumn{7}{|l|}{ Season of $25(\mathrm{OH}) \mathrm{D}$ draw } \\
\hline Autumn & 925 & 21 & 57 & 29 & 982 & 22 \\
\hline Spring & 1096 & 25 & 38 & 19 & 1134 & 25 \\
\hline Summer & 1035 & 24 & 61 & 31 & 1096 & 24 \\
\hline Winter & 1253 & 29 & 43 & 22 & 1296 & 29 \\
\hline $\begin{array}{l}\text { Vitamin D supplemental } \\
\text { use }^{*}\end{array}$ & 501 & 12 & 36 & 18 & 537 & 12 \\
\hline $90 \mathrm{~d}$ mortality & 284 & 7 & 47 & 24 & 331 & 7 \\
\hline
\end{tabular}

HANOD, hospital-acquired new-onset delirium; 25(OH)D, 25-hydroxyvitamin D.

*Vitamin D supplemental use refers to vitamin D supplementation in the year before hospitalisation. 
291.0-291.9, 292.81, 293.0-293.1, 293.9, 300.11, 308.09, 780.02 or 780.09 during hospitalisation ${ }^{(28,29)}$

\section{Comorbidities}

Data specific to age, sex and race for each patient was directly abstracted from the RPDR. We utilised the ICD-9-CM coding algorithms, which are well studied and validated ${ }^{(30,31)}$, to derive the Deyo-Charlson Index to assess the burden of chronic illness in our study cohort ${ }^{(32)}$. 'Patient Type' was defined as 'Medical' or 'Surgical' and incorporated the Diagnostic Related Group methodology ${ }^{(33)}$. Recent surgery data were obtained from operating room schedule records and was defined as a surgical procedure performed in the operating room before delirium diagnosis. Intensive care unit admission was determined by the assignment of Current Procedural Terminology code 99291 (critical care, first 30-74 min) during hospitalisation. The use of Current Procedural Terminology code 99291 in this manner has been previously validated in the RPDR database ${ }^{(25)}$. Chronic liver disease was determined by ICD-9-CM codes 571.xx, 70.54 and $70.32^{(34)}$. Sepsis was defined by the presence of any of the following ICD-9-CM codes during hospitalisation: $038.0-038.9 ; 020.0 ; 790.7 ; 117.9 ; 112.5112 .8^{(35)}$, with exclusion of sepsis occurring after a diagnosis of delirium. We have validated ICD-9-CM identification of sepsis in the RPDR database ${ }^{(36)}$. History of major depressive disorder was defined by the presence of ICD-9-CM codes $296.2 \mathrm{x}$ or $296.3 x$ before hospital admission ${ }^{(37)}$. Antipsychotic medication use was determined via pharmacy data of haloperidol, risperidone or olanzapine prescriptions during hospitalisation, since these were the antipsychotic medications on the hospital formularies over the study period.

\section{Assessment of mortality}

Information on vital status for the study cohort was obtained from the Social Security Administration Death Master File,

Table 2. Patient characteristics by pre-hospital vitamin D status

(Number of subjects and percentages; mean values and standard deviations)

\begin{tabular}{|c|c|c|c|c|c|c|c|c|c|}
\hline & \multicolumn{9}{|c|}{ Pre-hospital 25(OH)D } \\
\hline & \multicolumn{2}{|c|}{$<10 \mathrm{ng} / \mathrm{ml}$} & \multicolumn{2}{|c|}{$\begin{array}{c}10-199 \\
\mathrm{ng} / \mathrm{ml}\end{array}$} & \multicolumn{2}{|c|}{$\begin{array}{c}20-299 \\
\mathrm{ng} / \mathrm{ml}\end{array}$} & \multicolumn{2}{|c|}{$\geq 30 \mathrm{ng} / \mathrm{ml}$} & \multirow[b]{2}{*}{$P^{\star}$} \\
\hline & $n$ & $\%$ & $n$ & $\%$ & $n$ & $\%$ & $n$ & $\%$ & \\
\hline Number of cases & \multicolumn{2}{|c|}{742} & \multicolumn{2}{|c|}{1542} & \multicolumn{2}{|c|}{1342} & \multicolumn{2}{|c|}{882} & \\
\hline Age (years) & & & & & & & & & $0.012 \dagger$ \\
\hline Mean & \multicolumn{2}{|c|}{59} & \multicolumn{2}{|c|}{58} & \multicolumn{2}{|c|}{60} & \multicolumn{2}{|c|}{61} & \\
\hline SD & \multicolumn{2}{|c|}{18} & \multicolumn{2}{|c|}{18} & \multicolumn{2}{|c|}{18} & \multicolumn{2}{|c|}{18} & \\
\hline Sex & & & & & & & & & 0.001 \\
\hline Female & 472 & 64 & 980 & 64 & 879 & 66 & 630 & 71 & \\
\hline Male & 270 & 36 & 562 & 36 & 463 & 35 & 252 & 29 & \\
\hline Race & & & & & & & & & $<0.001$ \\
\hline White & 567 & 76 & 1248 & 81 & 1161 & 87 & 798 & 90 & \\
\hline Non-white & 175 & 24 & 294 & 19 & 181 & 13 & 84 & 10 & \\
\hline Patient type & & & & & & & & & $<0.001$ \\
\hline Medical & 511 & 69 & 909 & 59 & 759 & 57 & 476 & 54 & \\
\hline Surgical & 231 & 31 & 633 & 41 & 583 & 43 & 406 & 46 & \\
\hline Deyo-Charlson Index & & & & & & & & & $<0.001$ \\
\hline $0-3$ & 250 & 34 & 683 & 44 & 660 & 49 & 424 & 48 & \\
\hline $4-6$ & 202 & 27 & 415 & 27 & 325 & 24 & 223 & 25 & \\
\hline$\geq 7$ & 290 & 39 & 444 & 29 & 357 & 27 & 235 & 27 & \\
\hline Chronic liver disease & 182 & 25 & 403 & 26 & 324 & 24 & 184 & 21 & 0.036 \\
\hline Psychiatric primary diagnosis & 11 & 2 & 24 & 2 & 19 & 1 & 11 & 1 & 0.85 \\
\hline Major depressive disorder history & 25 & 3 & 51 & 3 & 53 & 4 & 19 & 2 & 0.14 \\
\hline Antipsychotic medications & 47 & 6 & 87 & 6 & 73 & 5 & 39 & 4 & 0.39 \\
\hline Vitamin D supplemental use $\ddagger$ & 126 & 17 & 194 & 13 & 121 & 9 & 96 & 11 & $<0.001$ \\
\hline Sepsis & 59 & 8 & 77 & 5 & 57 & 4 & 26 & 3 & $<0.001$ \\
\hline Bloodstream infection§ & 38 & 17 & 65 & 17 & 39 & 13 & 29 & 14 & 0.38 \\
\hline Leucocytes $\left(\times 10^{3} / \mu \mathrm{l}\right) \|$ & & & & & & & & & 0.061 \\
\hline $0-3 \cdot 9$ & 36 & 5 & 44 & 3 & 37 & 3 & 25 & 3 & \\
\hline $4 \cdot 0-9 \cdot 9$ & 354 & 48 & 705 & 46 & 649 & 48 & 432 & 49 & \\
\hline$>10$ & 352 & 47 & 793 & 51 & 656 & 49 & 425 & 48 & \\
\hline Creatinine $(>133 \mu \mathrm{mol} / \mathrm{l})$ & 261 & 35 & 350 & 23 & 256 & 19 & 152 & 17 & $<0.001$ \\
\hline ICU admission & 63 & 8 & 105 & 7 & 107 & 8 & 69 & 8 & 0.47 \\
\hline HANOD & 51 & 7 & 71 & 5 & 50 & 4 & 27 & 3 & 0.001 \\
\hline $90 \mathrm{~d}$ mortality & 78 & 11 & 133 & 9 & 76 & 6 & 44 & 5 & $<0.001$ \\
\hline
\end{tabular}

25(OH)D, 25-hydroxyvitamin D; ICU, intensive care unit; HANOD, hospital-acquired new-onset delirium.

${ }^{*} P$ values were determined by Kruskal-Wallis test.

$\dagger P$ value determined by $\chi^{2}$ test.

$\ddagger$ Vitamin D supplemental use refers to vitamin D supplementation in the year before hospitalisation.

$\S 1116$ patients with blood cultures drawn.

|| Leucocyte count measured at hospital admission. 
Table 3. Multivariable-adjusted associations between covariates and hospital-acquired new-onset delirium (HANOD)*

(Odds ratios and $95 \%$ confidence intervals)

\begin{tabular}{|c|c|c|c|}
\hline & OR & $95 \% \mathrm{Cl}$ & $P$ \\
\hline Age (per 1 year) & 1.02 & $1.01,1.03$ & $<0.001$ \\
\hline Sex & & & 0.55 \\
\hline Female & 1.00 & Reference & \\
\hline Male & $1 \cdot 10$ & $0.81,1.48$ & \\
\hline Race & & & 0.60 \\
\hline Non-white & 1.00 & Reference & \\
\hline White & 0.90 & $0.60,1.34$ & \\
\hline \multicolumn{4}{|l|}{ Patient type } \\
\hline Medical & 1.00 & Reference & 0.13 \\
\hline Surgical & 0.61 & $0.32,1 \cdot 15$ & \\
\hline \multicolumn{4}{|c|}{ Deyo-Charlson Index } \\
\hline $0-3$ & 1.00 & Reference & \\
\hline $4-6$ & 1.77 & $1 \cdot 19,2 \cdot 62$ & 0.005 \\
\hline$\geq 7$ & $2 \cdot 12$ & $1.46,3.09$ & $<0.001$ \\
\hline \multicolumn{4}{|c|}{ Pre-hospital 25(OH)D (ng/ml) } \\
\hline$<10$ & $2 \cdot 15$ & $1.32,3.50$ & 0.002 \\
\hline $10-19 \cdot 9$ & 1.54 & $0.98,2.43$ & 0.063 \\
\hline $20-29 \cdot 9$ & 1.23 & $0.76,1.99$ & 0.39 \\
\hline$\geq 30$ & 1.00 & Reference & \\
\hline
\end{tabular}

25(OH)D, 25-hydroxyvitamin D.

*Adjusted OR were estimated by a multivariable logistic regression model with inclusion of covariate terms considered to plausibly associate with vitamin D status and HANOD. Estimates for each variable are adjusted for all other variables in the table.

which has a reported sensitivity for mortality up to $92 \%$ and a specificity of $>99 \%{ }^{(38-41)}$. Utilisation of the Death Master File allows for long-term follow-up of patients after hospital discharge.

\section{Power calculations and statistical analysis}

Based on previous studies on HANOD susceptibility among hospitalised patients ${ }^{(2)}$, we assumed that delirium incidence would decrease from $10 \%$ in patients with pre-hospital $25(\mathrm{OH}) \mathrm{D}<20 \mathrm{ng} / \mathrm{ml}$ to $5 \%$ in those with pre-hospital $25(\mathrm{OH}) \mathrm{D} \geq 20 \mathrm{ng} / \mathrm{ml}$. With an $\alpha$ error level of $5 \%$ and a power of $80 \%$, the minimum sample size thus required for our primary end point (HANOD) is 1242 total patients.

Categorical variables were described by frequency distributions, and compared across $25(\mathrm{OH}) \mathrm{D}$ groups using contingency tables and $\chi^{2}$ testing. Continuous variables were examined graphically (e.g. histogram and box plot) and in terms of summary statistics, i.e. mean and standard deviation for normally distributed data or median and interquartile range for nonparametric data, and then compared across exposure groups using one-way ANOVA. The outcome considered was HANOD.

Unadjusted associations between $25(\mathrm{OH}) \mathrm{D}$ groups and HANOD were estimated by bivariable logistic regression models. Adjusted OR were estimated by multivariable logistic regression models, including a priori covariate terms considered to plausibly associate with both $25(\mathrm{OH}) \mathrm{D}$ levels and HANOD $^{(8)}$ to avoid unnecessarily adjusting for variables that do not affect bias or the causal relationship between exposure and outcome ${ }^{(42)}$. For the primary model (HANOD), specification of each continuous covariate (as a linear $v$. categorical term) was adjudicated by the empiric association with the primary outcome using Akaike's Information Criterion; overall model fit was assessed using the Hosmer-Lemeshow test. Models for secondary analyses were specified identically to the primary model. Unadjusted event rates were calculated with the use of the Kaplan-Meier methods and compared with the use of the log-rank test. Locally weighted scatter plot smoothing ${ }^{(43,44)}$ was used to graphically represent the relationship between pre-hospital 25(OH)D level and the risk of HANOD. All $P$-values are two-tailed, with values $<0.05$ considered statistically significant. All analyses were performed using Stata 12.0MP statistical software (Stata Corporation).

\section{Results}

Most patients were female, white and had a medical-related Diagnostic Related Group (Table 1). The mean age at hospital admission was 59 (SD 18) years. Approximately $4 \%$ of the cohort patients ( $n$ 198) met the criteria for HANOD. The mean 25(OH)D level was 22 (SD 13) ng/ml (to convert to $\mathrm{nmol} / 1$, multiply by 2.496$)$. The $45 \%$ of the $25(\mathrm{OH}) \mathrm{D}$ measurements occurred in the 3 months before hospital admission.

Patient characteristics of the study cohort were stratified according to pre-admission 25(OH)D levels (Table 2). Factors that significantly differed between stratified groups included age, sex, race, patient type (medical $v$. surgical), Deyo-Charlson Index and vitamin D supplementation use. 25(OH)D levels, age and Deyo-Charlson Index were found to be significant predictors of HANOD (Table 3). In-hospital, $30-\mathrm{d}$ and 90-d mortality rates were 3, 4 and $7 \%$, respectively.

\section{Primary outcome}

Low pre-admission vitamin D status was a strong predictor of HANOD after adjustment for age, sex, race, Deyo-Charlson Index and patient type (Table 4). The adjusted odds of HANOD in patients with $25(\mathrm{OH}) \mathrm{D}$ levels $<10 \mathrm{ng} / \mathrm{ml}$ and in those with levels $10-19 \cdot 9 \mathrm{ng} / \mathrm{ml}$ were $2 \cdot 2$ - and 1.5 -fold higher than in patients with $25(\mathrm{OH}) \mathrm{D}$ levels $\geq 30 \mathrm{ng} / \mathrm{ml}$,

Table 4. Unadjusted and adjusted associations between pre-hospital vitamin $D$ status and hospital-acquired new-onset delirium (HANOD)*

(Odds ratios and $95 \%$ confidence intervals, $n$ 4508)

\begin{tabular}{|c|c|c|c|c|}
\hline & \multicolumn{4}{|c|}{ Pre-hospital 25(OH)D } \\
\hline & $<10 \mathrm{ng} / \mathrm{ml}$ & $10-199 \mathrm{ng} / \mathrm{ml}$ & $20-299 \mathrm{ng} / \mathrm{ml}$ & $\geq 30 \mathrm{ng} / \mathrm{ml}$ \\
\hline \multicolumn{5}{|l|}{ Unadjusted } \\
\hline OR & $2 \cdot 34$ & 1.53 & 1.23 & 1.00 \\
\hline $95 \% \mathrm{Cl}$ & $1.45,3.77$ & $0.97,2.40$ & $0.76,1.97$ & Referent \\
\hline$P$ & $<0.001$ & 0.065 & 0.40 & \\
\hline \multicolumn{5}{|l|}{ Adjusted } \\
\hline OR & $2 \cdot 15$ & 1.54 & 1.23 & 1.00 \\
\hline $95 \% \mathrm{Cl}$ & $1.32,3.50$ & $0.98,2.43$ & $0.76,1.99$ & Referent \\
\hline$P$ & 0.002 & 0.063 & 0.39 & \\
\hline
\end{tabular}

25(OH)D, 25-hydroxyvitamin D.

* Unadjusted associations between 25(OH)D groups and HANOD were estimated by bivariable logistic regression models. Adjusted OR were estimated by multivariable logistic regression models with inclusion of covariate terms considered to plausibly associate with both $25(\mathrm{OH}) \mathrm{D}$ concentrations and HANOD. Estimates adjusted for age, sex, race (non-white $v$. white), patient type (medical $v$. surgical) and Deyo-Charlson Index. 
respectively (Table 4). Additional individual adjustment for potential confounders such as recent surgery, sepsis, history of major depression, antipsychotic drug medication use, leucocyte count or calcium on admission, chronic liver disease, season of $25(\mathrm{OH}) \mathrm{D}$ draw, the timing of the $25(\mathrm{OH}) \mathrm{D}$ draw relative to admission and intensive care unit admission did not materially alter these point estimates (Table 5).

\section{Secondary outcomes}

To assess the discrimination of $25(\mathrm{OH}) \mathrm{D}$ for HANOD, we used receiver-operating characteristic curve analysis and determined the AUC. Estimating the AUC showed that 25(OH)D had poor discriminative power for HANOD: $A U C=0.57$
(95\% CI $0.53,0.61)$. Locally weighted scatter plot smoothing plot (Fig. 1) showed a near inverse linear association between $25(\mathrm{OH}) \mathrm{D}$ level and the risk of HANOD up to $25(\mathrm{OH}) \mathrm{D}$ levels near $30 \mathrm{ng} / \mathrm{ml}$. Beyond 25(OH)D of $40 \mathrm{ng} / \mathrm{ml}$, the curve appears flat.

In the study cohort ( $n$ 4508), the HANOD rate in patients with pre-hospital $25(\mathrm{OH}) \mathrm{D}<10, \quad 10-19 \cdot 9, \quad 20-29 \cdot 9$ or $\geq 30 \mathrm{ng} / \mathrm{ml}$ was determined to be approximately 69, 46, 37 and 31 per 1000 inpatients, respectively; the overall incidence was determined to be forty-four per 1000 inpatients. Finally, HANOD is associated with all-cause mortality (Fig. 2). When HANOD is considered as the exposure and all-cause mortality the outcome, HANOD is associated with $90 \mathrm{~d}$ mortality: OR for 90-d mortality in patients with HANOD $3 \cdot 26$ (95\% CI $2 \cdot 27$,

Table 5. Adjusted associations between pre-hospital vitamin $D$ status and hospital-acquired new-onset delirium (HANOD)*

(Odds ratios and $95 \%$ confidence intervals, $n$ 4508)

\begin{tabular}{|c|c|c|c|c|}
\hline & \multicolumn{4}{|c|}{ Pre-hospital 25(OH)D } \\
\hline & $<10 \mathrm{ng} / \mathrm{ml}$ & $10-199 \mathrm{ng} / \mathrm{ml}$ & $20-299 \mathrm{ng} / \mathrm{ml}$ & $\geq 30 \mathrm{ng} / \mathrm{ml}$ \\
\hline \multicolumn{5}{|c|}{ Adjusted+recent surgery } \\
\hline OR & $2 \cdot 13$ & 1.51 & $1 \cdot 21$ & 1.00 \\
\hline $95 \% \mathrm{Cl}$ & $1 \cdot 30,3.48$ & $0.96,2.39$ & $0.75,1.96$ & Referent \\
\hline$P$ & 0.003 & 0.078 & 0.44 & \\
\hline \multicolumn{5}{|c|}{ Adjusted+sepsis } \\
\hline OR & 2.04 & 1.51 & $1 \cdot 21$ & 1.00 \\
\hline $95 \% \mathrm{Cl}$ & $1.25,3.33$ & $0.96,2.39$ & $0.75,1.96$ & Referent \\
\hline$P$ & 0.004 & 0.076 & 0.43 & \\
\hline \multicolumn{5}{|c|}{ Adjusted+depression } \\
\hline OR & $2 \cdot 14$ & 1.53 & 1.20 & 1.00 \\
\hline $95 \% \mathrm{Cl}$ & $1.32,3.48$ & $0.97,2.42$ & $0.74,1.94$ & Referent \\
\hline$P$ & 0.002 & 0.067 & 0.45 & \\
\hline \multicolumn{5}{|c|}{ Adjusted+antipsychotics } \\
\hline OR & 2.01 & 1.45 & $1 \cdot 15$ & 1.00 \\
\hline $95 \% \mathrm{Cl}$ & $1 \cdot 21,3.35$ & $0.91,2.33$ & $0.70,1.90$ & Referent \\
\hline$P$ & 0.007 & 0.12 & 0.57 & \\
\hline \multicolumn{5}{|c|}{ Adjusted+leucocyte count } \\
\hline OR & $2 \cdot 15$ & 1.52 & 1.23 & 1.00 \\
\hline $95 \% \mathrm{Cl}$ & $1.32,3.49$ & $0.97,2.41$ & $0.76,1.99$ & Referent \\
\hline$P$ & 0.002 & 0.069 & 0.40 & \\
\hline \multicolumn{5}{|c|}{ Adjusted $+\mathrm{Ca}$} \\
\hline OR & $2 \cdot 15$ & 1.55 & 1.24 & 1.00 \\
\hline $95 \% \mathrm{Cl}$ & $1.33,3.50$ & $0.98,2.44$ & $0.77,2.01$ & Referent \\
\hline$P$ & 0.002 & 0.061 & 0.38 & \\
\hline \multicolumn{5}{|c|}{ Adjusted+liver disease } \\
\hline OR & $2 \cdot 16$ & 1.54 & 1.23 & 1.00 \\
\hline $95 \% \mathrm{Cl}$ & $1.33,3.51$ & $0.98,2.43$ & $0.76,1.99$ & Referent \\
\hline$P$ & 0.002 & 0.063 & 0.39 & \\
\hline \multicolumn{5}{|c|}{$\begin{array}{l}\text { Adjusted+season } \\
\text { of } 25(\mathrm{OH}) \mathrm{D} \text { draw }\end{array}$} \\
\hline OR & $2 \cdot 14$ & 1.51 & 1.21 & 1.00 \\
\hline $95 \% \mathrm{Cl}$ & $1.30,3.49$ & $0.96,2.40$ & $0.75,1.96$ & Referent \\
\hline$P$ & 0.003 & 0.076 & 0.43 & \\
\hline \multicolumn{5}{|c|}{ Adjusted+timing of $25(\mathrm{OH}) \mathrm{D}$ draw } \\
\hline OR & 2.09 & 1.52 & 1.23 & 1.00 \\
\hline $95 \% \mathrm{Cl}$ & $1 \cdot 28,3.41$ & $0.97,2.40$ & $0.76,1.99$ & Referent \\
\hline$P$ & 0.003 & 0.071 & 0.39 & \\
\hline \multicolumn{5}{|c|}{ Adjusted+ICU admission } \\
\hline OR & $2 \cdot 22$ & 1.61 & 1.23 & 1.00 \\
\hline $95 \% \mathrm{Cl}$ & $1.36,3.62$ & $1.01,2.55$ & $0.76,2.00$ & Referent \\
\hline$P$ & 0.001 & 0.043 & 0.40 & \\
\hline
\end{tabular}




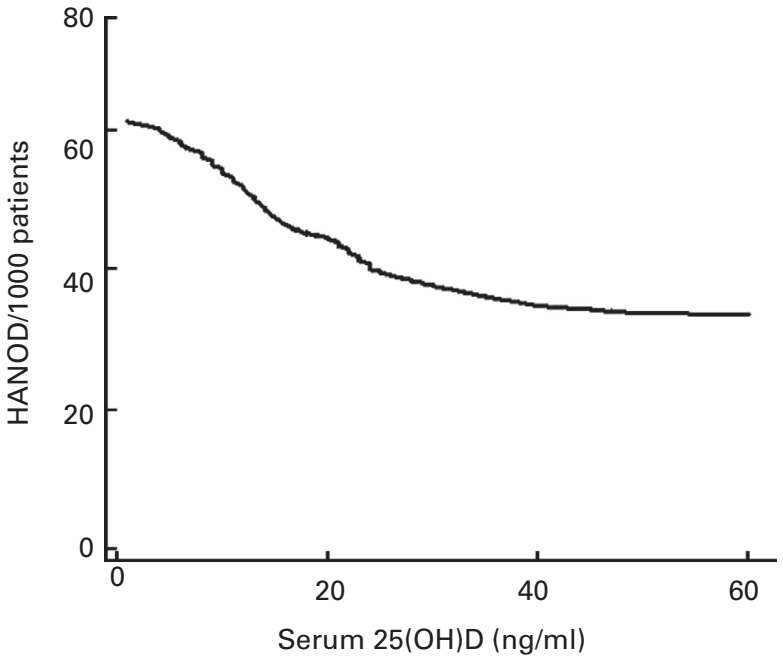

Fig. 1. Vitamin D status $v$. the risk of hospital-acquired new-onset delirium. Locally weighted scatter plot smoothing utilised to represent the near inverse linear association between pre-hospital 25-hydroxyvitamin $\mathrm{D}(25(\mathrm{OH}) \mathrm{D})$ level and the risk of hospital-acquired new-onset delirium (HANOD). Plot constructed with data from inpatients ( $n$ 4508) with pre-hospital vitamin D status excluding patients with existing history of delirium or dementia, and those with the diagnosis of delirium or dementia on admission.

4.69) relative to those without HANOD adjusted for age, sex, race, patient type and Deyo-Charlson Index. When further adjusted for $25(\mathrm{OH}) \mathrm{D}$ status, the OR for 90 -d mortality in patients with HANOD is $3 \cdot 12$ (95\% CI $2 \cdot 17,4 \cdot 50)$ relative to those without HANOD adjusted for age, sex, race, patient type, Deyo-Charlson Index and 25(OH)D level.

\section{Effect modification}

Analyses based on fully adjusted models were performed to evaluate the $25(\mathrm{OH}) \mathrm{D}-\mathrm{HANOD}$ association, and $P$ for interaction was determined to explore for any evidence of effect modification. We individually tested for effect modification by creatinine, season of $25(\mathrm{OH}) \mathrm{D}$ draw, time between $25(\mathrm{OH}) \mathrm{D}$ draw and hospital admission or hospital of care by adding an interaction term to the multivariate models. None of these variables emerged as an effect modifier of the association between 25(OH)D and HANOD ( $P$ for interaction: HANOD $>0.20$ for all variables tested).

\section{Discussion}

In the present study, we investigated whether vitamin D status before hospitalisation was associated with the risk of HANOD. We demonstrated that pre-hospital $25(\mathrm{OH}) \mathrm{D}<10 \mathrm{ng} / \mathrm{ml}$ is indeed associated with a significant increase in the odds of delirium in patients during hospitalisation. While others have reported that vitamin D status may play an important protective role against various neuropsychiatric disorders ${ }^{(11-15)}$, the present study presents important evidence to suggest that vitamin D supplementation may provide a novel approach to lowering HANOD risk. However, due to the observational nature of the present study, causal inference of the relationship between vitamin D status and delirium is limited.
The observed association between 25(OH)D and HANOD is biologically plausible. Purkinje cells as well as other neurons in the cerebral cortex and hippocampus (the primary cognitive centres in the human brain) express the vitamin D receptors ${ }^{(13)}$. Binding of the $25(\mathrm{OH}) \mathrm{D}-$ vitamin $\mathrm{D}$ receptor complex to the nuclear vitamin $\mathrm{D}$ response element induces the synthesis of $1-\alpha$-hydroxylase ${ }^{(45)}$, which is critical for the paracrine conversion of $25(\mathrm{OH}) \mathrm{D}$ to 1,25 -dihydroxyvitamin D. As the most biologically active vitamin D metabolite in the central nervous system, 1,25-dihydroxyvitamin D upregulates hippocampal expression of neurotrophins ${ }^{(46)}$. Neurotrophins are a family of proteins that are critical for regulating the survival, differentiation and maintenance of nerve cells ${ }^{(47)}$. Brain-derived neurotrophic factor and nerve growth factor, two key members of the neurotrophin family, have both been shown to be directly associated with delirium following acute stress $^{(48,49)}$. In addition, vitamin D may contribute to neuroprotection by modulating the production of glial cell-derived neurotrophic factor, NO synthase and choline acetyl transferase ${ }^{(13)}$. Since it is evident that derangements in the cognitive pathways of the brain predispose patients to HANOD, and that vitamin D status is essential for both optimal nerve function and recovery following stress, the present findings raise a number of questions that merit further investigation.

The present study is not without potential limitations. Cohort studies may not provide the highest level of clinical evidence, but may direct future research by illustrating the existence or absence of a true effect ${ }^{(50)}$. Observational studies may also be limited by confounding, reverse causation and/or the lack of a randomly distributed exposure. Since the patient cohort under the study had vitamin D status measurements related to an unknown reason (e.g. work-up for malnutrition, comprehensive immunological work-ups and monitoring for endocrine disorders), which may be absent in other hospitalised patients, ascertainment bias may exist in the present study. These differences may decrease the generalisability of the present results to all hospitalised patients. Despite adjustment for multiple potential confounders, there may still be residual confounding that contributed to the observed differences in outcomes. Specifically, low 25(OH)D levels may

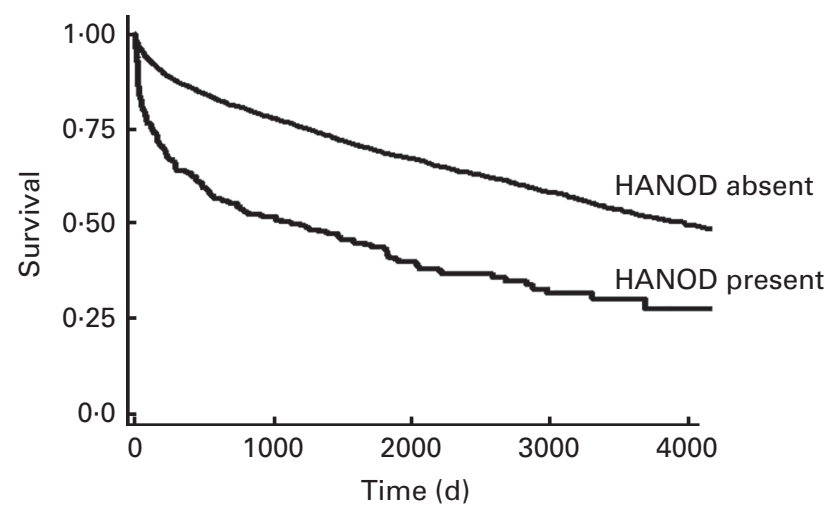

Fig. 2. Time-to-event curves for the secondary end point (mortality). Unadjusted event rates were calculated with the use of Kaplan-Meier methods and compared with the use of the log-rank test. The global comparison log rank $P$ value is $<0.0001$ ( $n$ 4508). HANOD, hospital-acquired new-onset delirium. 
be a marker for the general condition of patients (i.e. the combined effect of nutritional status, functional mobility and chronic systemic diseases), for which we are unable to fully adjust.

A further potential limitation is related to the fact that we utilised 25(OH)D measurements between 7 and $365 \mathrm{~d}$ before hospitalisation as a reflection of pre-hospital vitamin D status. Others have shown that the intra-person Pearson correlation coefficient for $25(\mathrm{OH}) \mathrm{D}$ in outpatients following adjustments for age, race and season is 0.70 at 3 years between blood draws ${ }^{(51)}$. In our cohort, there was no interaction of the $25(\mathrm{OH}) \mathrm{D}-\mathrm{HANOD}$ association with regard to when $25(\mathrm{OH}) \mathrm{D}$ was obtained. Despite this observation, vitamin D status at the time of hospitalisation may be different than when prehospital values were drawn. Indeed, inflammatory changes, intravenous fluid administration and renal wasting may significantly contribute to rapid drops (approximately 30-40\%) in circulating $25(\mathrm{OH}) \mathrm{D}$ levels during acute stress ${ }^{(52)}$. And although sunlight exposure, nutritional status (beyond the use of BMI), frailty/functional status and alcohol consumption are all potentially important confounders that may affect the $25(\mathrm{OH}) \mathrm{D}-\mathrm{HANOD}$ relationship, given the limitations of our present electronic database, we are unable to adjust for these covariates. These issues will need to be addressed by other groups as they try to replicate and extend our finding.

The present study has several strengths. We have sufficient statistical power to detect a clinically relevant difference in HANOD. We were able to control for several well-known risk factors for HANOD such as age, sex, recent surgery, use of antipsychotic medications, serious infections and a history of major depression. In addition, the Deyo-Charlson Index allowed us to account for chronic medical comorbidities. Moreover, by our design of measuring vitamin D status before hospitalisation, we attempted to uncouple the influence of illness and inflammation on 25(OH)D levels; we did not include $25(\mathrm{OH}) \mathrm{D}$ levels drawn in the $7 \mathrm{~d}$ before hospitalisation to avoid any potential alterations of vitamin D status related to acute illness or inflammation.

\section{Conclusion}

In conclusion, the present results suggest that pre-hospital vitamin $\mathrm{D}$ status may be a modifiable risk factor for HANOD. We hypothesise that serum 25(OH)D levels are associated with optimal expression of endogenous proteins involved with the maintenance of neuronal health in the areas of the central nervous system responsible for cognition. In turn, this may attenuate the effect of acute stressors that may increase the risk of HANOD. Prospective studies are needed to validate our findings, to assess the potential benefit of optimising pre-hospital $25(\mathrm{OH}) \mathrm{D}$ levels, and to identify the mechanism by which vitamin $\mathrm{D}$ may confer protection against neuropsychiatric disorders such as HANOD.

\section{Acknowledgements}

This manuscript is dedicated to the memory of our dear friend and colleague Nathan Edward Hellman, MD, PhD.
S. A. Q. was financially supported by the US National Institutes of Health 5T32GM007592 and UL1 RR025758. C. A. C. was supported by the US National Institutes of Health R01 AI093723 and U01 AI087881. K. B. C. was supported by the US National Institutes of Health K08AI060881.

The authors declare that there are no conflicts of interest.

The authors' contributions are as follows: S. A. Q. and K. B. C. jointly conceived the study as well as designed and implemented the analysis with assistance from C. A. C.; K. B. C. and K. M. E. assembled the input data, wrote the code, ran the model and analysed the output data; S. A. Q., C. A. C. and K. B. C. wrote the manuscript; S. A. Q., A. A. L., K. M. E., F. K. G., E. G., C. A. C. and K. B. C. edited the manuscript and provided conceptual advice.

\section{References}

1. American Psychiatric Association (2006) Diagnostic and Statistical Manual of Mental Disorders, 5th ed. Washington, DC: American Psychiatric Association.

2. Siddiqi N, House AO \& Holmes JD (2006) Occurrence and outcome of delirium in medical in-patients: a systematic literature review. Age Ageing 35, 350-364.

3. Reston JT \& Schoelles KM (2013) In-facility delirium prevention programs as a patient safety strategy: a systematic review. Ann Intern Med 158, 375-380.

4. Inouye SK, Viscoli CM, Horwitz RI, et al. (1993) A predictive model for delirium in hospitalized elderly medical patients based on admission characteristics. Ann Intern Med 119, $474-481$

5. Marcantonio ER, Goldman L, Mangione CM, et al. (1994) A clinical prediction rule for delirium after elective noncardiac surgery. JAMA 271, 134-139.

6. Rudolph JL, Jones RN, Levkoff SE, et al. (2009) Derivation and validation of a preoperative prediction rule for delirium after cardiac surgery. Circulation 119, 229-236.

7. McCusker J, Cole M, Dendukuri N, et al. (2001) Delirium in older medical inpatients and subsequent cognitive and functional status: a prospective study. CMAJ 165, 575-583.

8. Leslie DL, Marcantonio ER, Zhang Y, et al. (2008) One-year health care costs associated with delirium in the elderly population. Arch Intern Med 168, 27-32.

9. Siddiqi N \& House A (2006) Delirium: an update on diagnosis, treatment and prevention. Clin Med 6, 540-543.

10. Kalueff AV \& Tuohimaa P (2007) Neurosteroid hormone vitamin D and its utility in clinical nutrition. Curr Opin Clin Nutr Metab Care 10, 12-19.

11. Buell JS \& Dawson-Hughes B (2008) Vitamin D and neurocognitive dysfunction: preventing "D"ecline? Mol Aspects Med 29, 415-422.

12. Annweiler C, Allali G, Allain P, et al. (2009) Vitamin D and cognitive performance in adults: a systematic review. Eur J Neurol 16, 1083-1089.

13. Balion C, Griffith LE, Strifler L, et al. (2012) Vitamin D, cognition, and dementia: a systematic review and meta-analysis. Neurology 79, 1397-1405.

14. Annweiler C, Llewellyn DJ \& Beauchet O (2013) Low serum vitamin D concentrations in Alzheimer's disease: a systematic review and meta-analysis. J Alzheimers Dis 33, 659-674.

15. Anglin RE, Samaan Z, Walter SD, et al. (2013) Vitamin D deficiency and depression in adults: systematic review and meta-analysis. Br J Psychiatry 202, 100-107. 
16. Kuriacose R \& Olive KE (2008) Prevalence of vitamin D deficiency and insufficiency in northeast Tennessee. South Med J 101, 906-909.

17. Pellicane AJ, Wysocki NM \& Schnitzer TJ (2010) Prevalence of 25-hydroxyvitamin D deficiency in the outpatient rehabilitation population. Am J Phys Med Rehabil 89, 899-904.

18. Fish E, Beverstein G, Olson D, et al. (2010) Vitamin D status of morbidly obese bariatric surgery patients. J Surg Res $\mathbf{1 6 4}$, 198-202.

19. Bogunovic L, Kim AD, Beamer BS, et al. (2010) Hypovitaminosis $\mathrm{D}$ in patients scheduled to undergo orthopaedic surgery: a single-center analysis. J Bone Joint Surg Am 92, 2300-2304.

20. Ginde AA, Liu MC, Camargo CA, et al. (2009) Demographic differences and trends of vitamin D insufficiency in the US population, 1988-2004. Arch Intern Med 169, 626-632.

21. Braun A, Chang D, Mahadevappa K, et al. (2011) Association of low serum 25-hydroxyvitamin D levels and mortality in the critically ill. Crit Care Med 39, 671-677.

22. Hivert MF, Grant RW, Shrader P, et al. (2009) Identifying primary care patients at risk for future diabetes and cardiovascular disease using electronic health records. BMC Health Serv Res 9, 170.

23. Hug BL, Lipsitz SR, Seger DL, et al. (2009) Mortality and drug exposure in a 5 -year cohort of patients with chronic liver disease. Swiss Med Wkly 139, 737-746.

24. Linder JA, Bates DW, Williams DH, et al. (2006) Acute infections in primary care: accuracy of electronic diagnoses and electronic antibiotic prescribing. J Am Med Inform Assoc 13, 61-66.

25. Zager S, Mendu ML, Chang D, et al. (2011) Neighborhood poverty rate and mortality in patients receiving critical care in the academic medical center setting. Chest 139, 1368-1379.

26. Holick MF, Binkley NC, Bischoff-Ferrari HA, et al. (2011) Evaluation, treatment, and prevention of vitamin D deficiency: an Endocrine Society clinical practice guideline. J Clin Endocrinol Metab 96, 1911-1930.

27. Hollis BW, Kamerud JQ, Selvaag SR, et al. (1993) Determination of vitamin D status by radioimmunoassay with an ${ }^{125}$ I-labeled tracer. Clin Chem 39, 529-533.

28. Inouye SK, Leo-Summers L, Zhang Y, et al. (2005) A chartbased method for identification of delirium: validation compared with interviewer ratings using the confusion assessment method. J Am Geriatr Soc 53, 312-318.

29. Swan JT, Fitousis K, Hall JB, et al. (2012) Antipsychotic use and diagnosis of delirium in the intensive care unit. Crit Care 16, R84.

30. Quan H, Sundararajan V, Halfon P, et al. (2005) Coding algorithms for defining comorbidities in ICD-9-CM and ICD-10 administrative data. Med Care 43, 1130-1139.

31. Quan H, Li B, Couris CM, et al. (2011) Updating and validating the Charlson comorbidity index and score for risk adjustment in hospital discharge abstracts using data from 6 countries. Am J Epidemiol 173, 676-682.

32. Charlson ME, Pompei P, Ales KL, et al. (1987) A new method of classifying prognostic comorbidity in longitudinal studies: development and validation. J Chronic Dis 40, 373-383.

33. Rapoport J, Gehlbach S, Lemeshow S, et al. (1992) Resource utilization among intensive care patients. Managed care vs traditional insurance. Arch Intern Med 152, 2207-2212.
34. Glasgow RE, Showstack JA, Katz PP, et al. (1999) The relationship between hospital volume and outcomes of hepatic resection for hepatocellular carcinoma. Arch Surg 134, 30-35.

35. Martin GS, Mannino DM, Eaton S, et al. (2003) The epidemiology of sepsis in the United States from 1979 through 2000. New Engl J Med 348, 1546-1554.

36. Moromizato T, Litonjua AA, Braun AB, et al. (2014) Association of low serum 25-hydroxyvitamin d levels and sepsis in the critically ill. Crit Care Med 42, 97-107.

37. Busch SH (2002) Specialty health care, treatment patterns, and quality: the impact of a mental health carve-out on care for depression. Health Serv Res 37, 1583-1601.

38. Cowper DC, Kubal JD, Maynard C, et al. (2002) A primer and comparative review of major US mortality databases. Ann Epidemiol 12, 462-468.

39. Sohn MW, Arnold N, Maynard C, et al. (2006) Accuracy and completeness of mortality data in the Department of Veterans Affairs. Popul Health Metr 4, 2.

40. Schisterman EF \& Whitcomb BW (2004) Use of the Social Security Administration Death Master File for ascertainment of mortality status. Popul Health Metr 2, 2.

41. Newman TB \& Brown AN (1997) Use of commercial record linkage software and vital statistics to identify patient deaths. J Am Med Inform Assoc 4, 233-237.

42. Schisterman EF, Cole SR \& Platt RW (2009) Overadjustment bias and unnecessary adjustment in epidemiologic studies. Epidemiology 20, 488-495.

43. Cleveland W (1979) Robust locally weighted regression and smoothing scatterplots. J Am Stat Assoc 74, 829-836.

44. Cleveland W \& Devlin S (1988) Locally-weighted regression: an approach to regression analysis by local fitting. J Am Stat Assoc 83, 596-610.

45. Zehnder D, Bland R, Williams MC, et al. (2001) Extrarenal expression of 25-hydroxyvitamin $\mathrm{D}(3)-1 \alpha$-hydroxylase. $J$ Clin Endocrinol Metab 86, 888-894.

46. McCann JC \& Ames BN (2008) Is there convincing biological or behavioral evidence linking vitamin D deficiency to brain dysfunction? FASEB J 22, 982-1001.

47. Glade MJ (2012) A 21st century evaluation of the safety of oral vitamin D. Nutrition 28, 344-356.

48. Grandi C, Tomasi CD, Fernandes K, et al. (2011) Brainderived neurotrophic factor and neuron-specific enolase, but not $S 100 \beta$, levels are associated to the occurrence of delirium in intensive care unit patients. J Crit Care 26, $133-137$.

49. Jockers-Scherubl MC, Bauer A, Kuhn S, et al. (2007) Nerve growth factor in serum is a marker of the stage of alcohol disease. Neurosci Lett 419, 78-82.

50. Concato J, Shah N \& Horwitz RI (2000) Randomized, controlled trials, observational studies, and the hierarchy of research designs. New Engl J Med 342, 1887-1892.

51. Platz EA, Leitzmann MF, Hollis BW, et al. (2004) Plasma 1,25-dihydroxy- and 25-hydroxyvitamin D and subsequent risk of prostate cancer. Cancer Causes Control 15, 255-265.

52. Quraishi SA \& Camargo CA Jr (2012) Vitamin D in acute stress and critical illness. Curr Opin Clin Nutr Metab Care 15, 625-634. 